\title{
Environmental Controlling Factors of Tasar Silkworms Antheria mylitta Drury (Lepidoptera : Saturniidae)
}

\author{
Amit Ranjan ${ }^{1}$, Anjana Poddar $^{2}$ and S.P. Roy ${ }^{3}$ \\ $1^{*}$ Univ. Dept. of Zoology, Tilkamanjhi Bhagalpur University,Bhagalpur-812007, Bihar (India) \\ ${ }^{2}$ Dept. of Commerce, Muslim Minority College, Bhagalpur, TM Bhagalpur University, Bhagalpur-812007 \\ ${ }^{3}$ Univ. Dept. of Zoology, Tilkamanjhi Bhagalpur University, Bhagalpur-812007, Bihar (India) \\ *Email:amitranjanbgp@gmail.com
}

\begin{abstract}
The paper deals with the ovipositioin, hatchability, fecundity larval and pupal performances of a tropical variety of tasar silkworms Antheria mylitta Drury (Lepidoptera : Saturniidae). The Tasar silkworms have been cultured feeding on the leaves of Arjun (Terminalia arjuna) in the laboratory at temperature $30^{\circ} \mathrm{C}$ and humidity $86 \%$ which has been recorded congenial for the hatching of the larvae. It was estimated that a potent female laid 285 eggs which are all variable and hatched into first instar larvae i.e. of 7 days each. Such a high reproductive potential of tasar silkworms will be beneficial for tasar production which has high value in the trade and commerce.
\end{abstract}

Key words: Life cycle, ecological diversity, oviposition, hatchability, cocoon formation, silk production.

\section{Introduction}

The present eco-race Antheria mylitta Drury is a Daba whose voltinism are found to be controlled by the environmental factors such as humidity and photoperiod. The combination of temperature and humidity provide optimum condition for hatching of the eggs. The optimum temperature $\left(28^{\circ} \mathrm{C}-\right.$ $30^{\circ} \mathrm{C}$ ) and humidity (75-86\%), photoperiod (100-242 hours per month) with (11-12.50 hours) day length were found favourable for the life cycle performance of this species of tasar silkworms. It was observed that decreasing temperature and increasing photoperiod had positive role in the moulting had positive role in the moulting and cocoon formation of the Antheria mylitta in the laboratory. The life cycle of the silkworms and growth of the host plants have been under the influence of temperature (Upadhyay and Mishra, 1991), Relative humidity (Mishra and Upadhyay, 1992), Photoperiod (Mishra and Upadhyay, 1992), Photoperiod (Mishra and Upadhyay, 1993), Ranjan and Roy (2009) artificial diet (Iwanvat and Ono, 1969) etc. for the performances of the life cycle of silkworms. The perusal of literature on the life cycle performances of Antheria mylitta indicates that no information is available on the controlling factors of the larval duration of this silkworm species. Keeping this is view present study has been undertaken to study the controlling factors of the life cycle of the worm in laboratory condition.

\section{Materials and methods}

The egg and adults of tropical tasar silkworms Antheria mylitta Drury were 
Amit Ranjan, Anjana Poddar and S.P. Roy / Our Nature (2012) 10: 115-118

Table 1: Monthly meteorological factors of Bhagalpur during June 2006-08.

\begin{tabular}{|c|c|c|c|c|c|c|c|}
\hline \multirow[t]{2}{*}{ Month } & \multicolumn{2}{|c|}{$\operatorname{Temp}^{\circ} \mathrm{C}$} & \multirow{2}{*}{$\begin{array}{c}\text { Rainfall } \\
\mathbf{m m}\end{array}$} & \multirow{2}{*}{$\begin{array}{c}\text { No. of } \\
\text { Rainy Days }\end{array}$} & \multicolumn{2}{|c|}{ RH (\%) } & \multirow{2}{*}{$\begin{array}{c}\text { Wind } \\
\text { Velocity } \\
\text { Km/hr }\end{array}$} \\
\hline & Max & Min & & & 7.00 A.M. & 2.00 P.M. & \\
\hline June'06 & 37.6 & 25.8 & 169.0 & 10 & 86 & 67 & 6.1 \\
\hline July & 33.0 & 26.5 & 265.0 & 21 & 89 & 73 & 6.9 \\
\hline Aug & 33.1 & 26.1 & 110.3 & 21 & 87 & 73 & 7.4 \\
\hline Sep & 31.5 & 25.2 & 490.2 & 16 & 92 & 77 & 7.7 \\
\hline Oct & 32.3 & 22.3 & 35.2 & 11 & 93 & 64 & 2.6 \\
\hline Nov & 27.5 & 16.0 & 06.0 & 05 & 93 & 60 & 2.9 \\
\hline Dec & 24.5 & 10.2 & 00.0 & 03 & 97 & 52 & 3.1 \\
\hline Jan'07 & 21.9 & 6.6 & 00.0 & 00 & 97 & 46 & 3.4 \\
\hline Feb & 24.1 & 11.4 & 17.1 & 00 & 95 & 59 & 4.1 \\
\hline Mar & 29.9 & 14.5 & 29.9 & 03 & 83 & 41 & 5.3 \\
\hline Apr & 36.9 & 21.8 & 06.0 & 04 & 76 & 42 & 7.4 \\
\hline May & 36.5 & 24.3 & 39.0 & 02 & 76 & 50 & 6.2 \\
\hline Jun & 34.1 & 24.5 & 06.1 & 08 & 86 & 66 & 8.8 \\
\hline Jul & 31.6 & 25.6 & 520.1 & 16 & 95 & 80 & 7.7 \\
\hline Aug & 31.8 & 26.5 & 110.1 & 24 & 90 & 76 & 7.3 \\
\hline Sep & 32.0 & 25.8 & 317.9 & 0916 & 91 & 80 & 6.4 \\
\hline Oct & 31.1 & 22.5 & 74.5 & 03 & 90 & 70 & 3.0 \\
\hline Nov & 28.9 & 16.1 & 00.0 & 00 & 94 & 55 & 2.7 \\
\hline Dec & 23.7 & 8.7 & 00.0 & 00 & 97 & 52 & 3.0 \\
\hline Jan'08 & 21.7 & 8.9 & 46.7 & 04 & 94 & 57 & 3.7 \\
\hline Feb & 23.4 & 9.9 & 0.4 & 02 & 92 & 50 & 4.1 \\
\hline Mar & 31.5 & 16.6 & 0.6 & 01 & 88 & 45 & 4.3 \\
\hline Apr & 36.4 & 20.8 & 13.5 & 02 & 79 & 35 & 6.5 \\
\hline May & 36.1 & 23.8 & 73.2 & 07 & 80 & 51 & 7.7 \\
\hline Jun & 33.5 & 25.2 & 350.9 & 17 & 90 & 73 & 7.9 \\
\hline
\end{tabular}

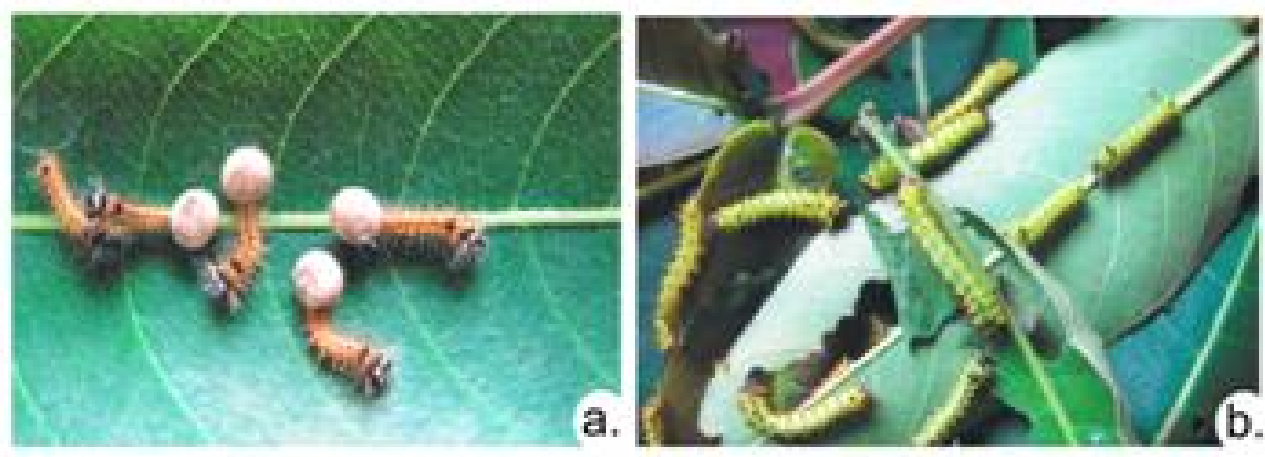


Amit Ranjan, Anjana Poddar and S.P. Roy / Our Nature (2012) 10: 115-118
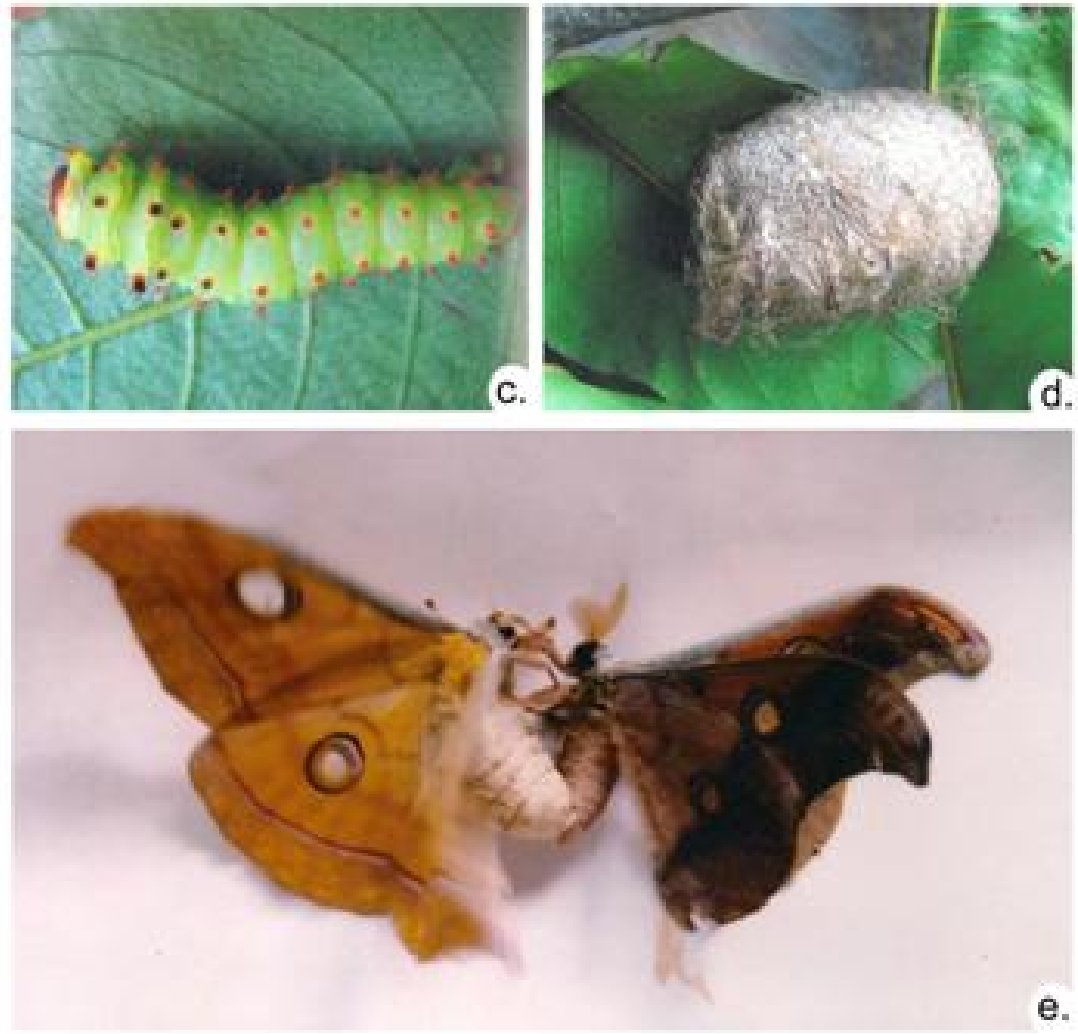

a) Emerging larva from egg.

b) Emerged larva.

c) Caterpillar of Antheria mylitta.

d) Cocoon formation.

e) Mating of male and female of Antheria mylitta.

Plate 1. Whole cycle of Antheria mylitta

obtained from the Central Silk Board, Sabour (Bhagalpur) and were maintained in the plywood trays $(23 \times 20 \times 5 \mathrm{~cm})$ under the ideal rearing condition (Khrisnaswami et.al. $1973 b)$ in the laboratory. The temperature and humidity were maintained at $27 \pm 1^{\circ} \mathrm{C}$ and $80 \pm 5 \%$. RH respectively until the emergence of the $1^{\text {st }}$ instar larvae from the eggs. The larval were provided with Arjun leaves for feeding and larval duration was noted. The emergence of adult from cocoon was studied as per description given by Krisnaswami et.al. (1973b). The newly emerged moth showed a tendency to pair immediately after the emergence and were allowed to mate at $27 \pm 1^{\circ} \mathrm{C}$ and $80 \pm 5 \%$. RH in $12 \pm 1$ hours dim light condition. After 4 hours of mating the paired moths wave decoupled manually. The female moth allowed to lays egg. The laid eggs were 
counted. The hatching time and larvel growth period noted till the formation of cocoon in the laboratory. The meteorological factors controlling the life cycle performances of Antheria mylitta were obtained from the meteorological observatory, Sabour Agriculture College, Bhagalpur.

\section{Results and discussion}

Antheria mylitta is a tropical silkworm species. In all the onset of rearing of silk by this species is strictly under the control of physical factors (Table-1) especially the temperature and humidity (Kogue, 1933). The weather conditions during the period of June 2007 to June 2008 indicated that the months November and December in both the years were found suitable for the culture of this silkworm species in the laboratory. This observation is in conformity with works of Upadhay and Mishra (1991, 1992). The whole cycle of Antheria mylitta completed in 32 days (Plate-I). The female laid 285 eggs in scattered manner. It was estimated that a potent female laid 285 eggs which are all variable and hatched into first instar larvae. The life cycle completed in 32 days with equal duration of $3^{\text {rd }}$ to $5^{\text {th }}$ instar larvae i.e. of 7 days each. These performances of tasar silkworms provide a high amount of raw silk resources to the society and add more to gross domestic production.

\section{References}

Iwanvat, Y. and Ono, Y. 1969. Rearing experiments on artificial diet composed mainly on the mulberry beat powder harvested in the late autumn and after. J. Seric. Sci., 38: 307-315.

Kogure, M. 1933.The influence of light and temperature on certain characters of the silkworm, B. mori Dept. Agri., Kyushu Imp. Univ., 4 (6): 193.

Mishra, A.B.; Upadhyay, V.B. 1992. Nutritional efficiency of bivoltine, Bombyx mori Linn. larvae at higher regimes of relative humidity. J.Adv. Zool. 13 (1 \& 2):16-18.

Mishram A.B.; Upadhyay, V.B. 1993.Nutritional efficacy of bivoltine, Bombyx mori Linn. larvae at different photoperiod. Proc. $80^{\text {th }}$ Session India Science Congress, Goa, pp. 54-55.

Ranjan A.; Roy, S.P. 2009 . On some aspects of life cycle performances of mulberry silkworms (Lepidoptera: Bombycidae) and their controlling factors. The Bioscan, An International Quarterly Journal of Life Science, 4: 349-351.

Upadhyay, V.B.; Mishra, A.B. 1991.Nutritional ability of bivoltine silkworm Bombyx mori Linn. larvae at higher temperature regimes. $J . A d v$. Zool., 12 (1) : 56-59. 